\title{
Cyclopolycondensation. XIII.* Polymer Reactions of Polybenzoxazinones with Organic Base
}

\author{
Masaru Kurihara and Yoshichi Hagiwara \\ Pioneering Research and Development Laboratories, \\ Toray Industries, Inc., Otsu, Japan.
}

(Received April 3, 1970)

\begin{abstract}
Polymer reactions of polybenzoxazinones with organic bases such as ammonia and aniline were studied. From the ring-opening reaction of the benzoxazinone ring of polybenzoxozinone with an organic base, the corresponding polyamides having pendant amide groups were obtained quantitatively without the high decrease in molecular weight. The polyamide undergoes thermal cyclization along the polymer chain to again yield polybenzoxazinone by deamination reaction, whereas in the presence of lithium chloride or zinc chloride it yields fully aromatic polyquinazolone by thermal cyclodehydration. Polyquinazolone thus obtained has excellent thermal stability in nitrogen and in air.

KEY WORDS Polymer Reaction / Polybenzoxazinone / Polyquinazolone / Polyamide / Polyamide-acid / Deamination / Cyclopolycondensation / Thermally Stable Polymer/
\end{abstract}

In recent years, broad investigations on aromatic heterocycles in search of thermally stable polymers have been carried out by the solution polymerization method in polyphosphoric acid (PPA) or the low temperature solution polymerization method. In the course of studying cyclopolycondensation, ${ }^{2}$ new aromatic polybenzoxazinones of high molecular weight were prepared by the cyclopolycondensation of $4,4^{\prime}$ diamino-3, $3^{\prime}$-biphenyldicarboxylic acid with a variety of aromatic carbonyl compounds using the PPA solution polymerization technique ${ }^{3}$ or the low temperature solution polymerization technique. ${ }^{4}$

Polybenzoxazinone has the reactive benzoxazinone ring system in the polymer main chain, and it is presumed that the polymer reactions of polybenzoxazinone with nucleophilic agents provide polyamide derivatives from the ringopening reactions of the benzoxazinone ring.

2-Phenyl-4H-3,1-benzoxazinone was first reported by Friedländer and Wleugesl using the reaction of anthranilic acid with benzoyl chloride without solvent. It was reported that the reaction of 2-phenyl-4H-3,1-benzoxazine-4-one with

* Presented in part at SPSJ 18th Annual Meeting Kyoto, May, 1969. For Part XII of this series, see ref 1 . organic amine yielded in the first step the $o$ acylbenzamide, followed by cyclization to yield quinazolone in the second step. ${ }^{6}$ It was also stated that an inorganic catalyst such as zinc chloride was useful in obtaining quinazolone. In the absence of zinc chloride, 2-phenyl-4H-3,1benzoxazin-4-one was recovered quantitatively.

This suggests the possibility of the formation of polyquinazolone by the reaction of polybenzoxazinone with organic amine in the twostep reactions.

In the present paper, the author describes the model reaction of 2-phenyl-4H-3,1-benzoxazinone with organic amine and the first successful preparation of fully aromatic polyquinazolone using the polymer reaction of polybenzoxazinone with organic amine.

The aromatic polyamide (II) having pendant amide groups of high molecular weight are obtained as shown in eq 1 . The polyamide (II), an open-chain tractable precursor, was subjected to thermal cyclization along the polymer chain in the presence of an inorganic salt such as lithium chloride or zinc chloride to yield fully aromatic polyquinazolones with excellent thermal stability. However in the absence of a catalyst, such as an inorganic salt, the polyamide undergoes 


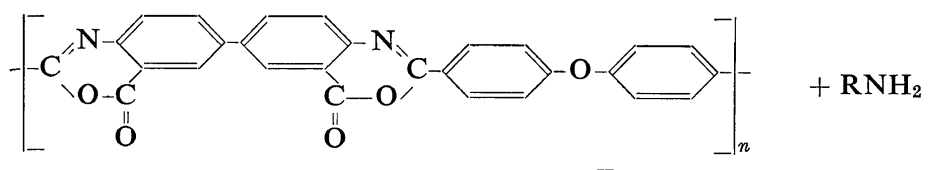

I $\quad \mathrm{R}=\mathrm{H}, \mathrm{C}_{6} \mathrm{H}_{5}$
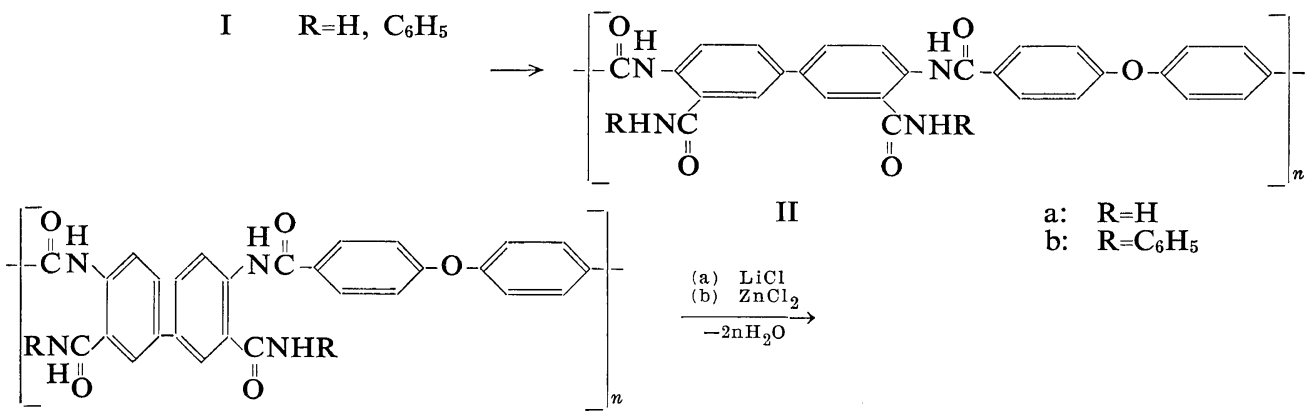

a: $\mathrm{R}=\mathrm{H}$

b: $\quad \mathrm{R}=\mathrm{C}_{6} \mathrm{H}_{5}$

II

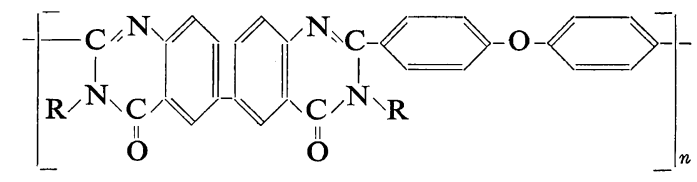

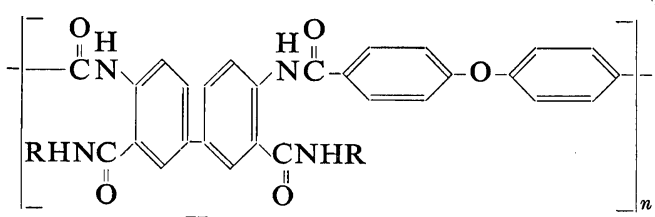

II
III

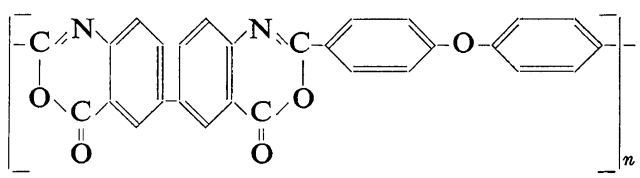

a: $\quad \mathrm{R}=\mathrm{H}\left(\mathrm{ZnCl}_{2}\right)$ thermal cyclodeamination along the polymer chain to again yield aromatic polybenzoxazinone (I).

\section{EXPERIMENTAL}

\section{Equipment}

All the melting points were measured on a Bücni melting point apparatus without correction. Microanalyses were carried out by the Microanalytical Section of this laboratory. Infrared spectra were recorded by a Hitachi Model EPI$S$ recording spectrophotometer on potassium bromide disks or film. Thermal gravimetric analyses (TGA) in nitrogen and air were obtained with a du Point-T-900 using $2-5 \mathrm{mg}$ of sample at the rate of $15^{\circ} \mathrm{C} / \mathrm{min}$.

\section{Materials}

Aromatic Polybenzoxazinone (I). This was prepared by the cyclopolycondensation of $4,4^{\prime}$ - diamino-3,3'-biphenyldicarboxylic acid with 4,4'oxydibenzoyl chloride in N-methylpyrrolidone, ${ }^{4}$ and polyamide acid thus obtained was subsequently subjected to thermal cyclodehydration along the polymer chain at $300-350^{\circ} \mathrm{C}$ in the second step, to give in quantitative yield a fully aromatic polybenzoxazinone. These polybenzoxazinone films were used as the starting materials and as the authentic sample of polybenzoxaxinone in this experiment.

$N$-Methyl-2-pyrrolidone (NMP). This was obtained from Kishida Chemical, C.P. grade, and was distilled with calcium hydride at $3 \mathrm{mmHg}$.

Orgamic Amine. Commercially available liquid ammonia and aniline (C.P. grade) were used.

Inorganic Salt. Commercially available lithium chloride and zinc chloride (C.P. grade) were used after drying in vacuo.

2-Phenyl-4H-3,1-benzoxazine-4-one (IV). This was prepared according to the procedure de- 
Cyclopolycondensation. XIII. Syntheses of Polyquinazolones

scribed in previous papers ${ }^{3,4}$ by the reaction of anthranilic acid with benzoyl chloride in polyphosphoric acid: $\mathrm{mp} 120.5^{\circ} \mathrm{C}$.

$o$-(Benzamide $)$ benzamide $(V)$. Method A. A mixture of $1.36 \mathrm{~g}(0.01 \mathrm{~mol})$ of anthranilamide prepared from isatoic anhydride and aqueous ammonia solution and $1.40 \mathrm{~g}$ of benzoyl chloride was added to $20 \mathrm{~m} l$ of tetrahydrofuran containing pyridine at $25^{\circ} \mathrm{C}$ and the solution was stirred for $1 \mathrm{hr}$ at $25^{\circ} \mathrm{C}$. The yield was $2.28 \mathrm{~g}(95.0 \%)$ : $\mathrm{mp} 212^{\circ} \mathrm{C}$. Recrystallization from $n$-hexaneethanol gave $\mathrm{V}$ as white crystals: $\mathrm{mp} 214^{\circ} \mathrm{C}$ (lit. ${ }^{7}$ $\mathrm{mp} 214^{\circ} \mathrm{C}$ ). Method B. Products prepared by the reaction of 2-phenyl-4H-3,1-benzoxazine-4one with aqueous ammonium solution at $85.2-\%$ yield were identical with those obtained by method A: $\mathrm{mp} 214^{\circ} \mathrm{C}$.

2-Phenyl-4-(3H)-quinazolone ( $V I)$. Method $A$. $1.00 \mathrm{~g}$ portion of $\mathrm{V}$ was kept at $260^{\circ} \mathrm{C}$ for $20 \mathrm{~min}$ in a test tube. The product was recrystallized from ethanol: yield, $0.64 \mathrm{~g}(69.4 \%) ; \mathrm{mp} 232^{\circ} \mathrm{C}$ (lit. ${ }^{8} \mathrm{mp} 232^{\circ} \mathrm{C}$ ). Method $B$. In the presence of a catalytic amount of $\mathrm{ZnCl}_{2}, 1.00 \mathrm{~g}$ of $\mathrm{V}$ was heated at $250^{\circ} \mathrm{C}$ for $20 \mathrm{~min}$. Crystallization of the product from ethanol gave VI at 50-\% yield as white crystals: mp. $231^{\circ} \mathrm{C}$. Method C. In the presence of a catalytic amount $\mathrm{LiCl}$, $1.00 \mathrm{~g}$ of $\mathrm{V}$ was heated at $250^{\circ} \mathrm{C}$ for $20 \mathrm{~min}$. Recrystallization from ethanol gave VI at 95-\% yield as white crystals: mp $232^{\circ} \mathrm{C}$.

2-3-Diphenyl-4(3H)-quinazolone $(V I I)^{8}$. This was prepared according to the procedure described in a previous paper $^{8}$ by the reaction of 2-phenyl$4 \mathrm{H}-3,1$-benzoxazine-4-one (IV) with aniline in the presence of $\mathrm{ZnCl}_{2}: \mathrm{mp} 177^{\circ} \mathrm{C}$.

The Authentic Sample of Polyamide $\left(I_{a}\right)$. This was prepared according to the procedure described in a previous paper ${ }^{4}$ using the low temperature solution polymerization method by the reaction of $4,4^{\prime}$-diamino-3,3'-biphenyldicarboxylamide $^{9}$ with $4,4^{\prime}$-oxydibenzoyl-chloride. $\eta_{\text {inh }}=0.85\left(0.5-\% \mathrm{NMP}, 30^{\circ} \mathrm{C}\right)$. The softening temperature was $345^{\circ} \mathrm{C}$.

Ring-Opening Reaction of Polybenzoxazinone (I) with Amines

The Reaction of Polybenzoxazinone with Liquid Ammonia $\left(I_{a}\right) .9 .6 \mathrm{~g}$ of polybenzoxazinone film (I) and $300 \mathrm{cc}$ of liquid ammonia were added in a three-necked flask cooled with Dry Ice- acetone, and the mixture was maintained at $-86^{\circ} \mathrm{C}$ for $24 \mathrm{hr}$. After removing the excess liquid ammonia at $25^{\circ} \mathrm{C}$ the precipitate obtained at $98-\%$ yield was extracted with NMP. The soluble part in NMP (90-\% yield) was precipitated with $1: 1 n$-hexane-methanol and dried at $120^{\circ} \mathrm{C}$ for $5 \mathrm{hr}$ in vacuo. $\eta_{\mathrm{inh}}=0.73(0.5-\%$ $\mathrm{H}_{2} \mathrm{SO}_{4}, 25^{\circ} \mathrm{C}$ ).

The Reaction of Polybenzoxazinone (I) with Aniline $\left(I_{a}\right) .20 \mathrm{mg}$ of polybenzoxazinone film (I) was added to $50 \mathrm{cc}$ of aniline and the mixture was refluxed at $184^{\circ} \mathrm{C}$. The soluble part in aniline was precipitated with chlorobenzene, to yield a white powder. The insoluble part in aniline was soluble in NMP.

\section{Cyclization of Polyamide (II)}

Thermal Cyclization of Polyamide $\left(I_{a}\right)$ in the Absence of Catalyst to Polybenzoxazinone. Polyamide film $\left(\mathrm{II}_{\mathrm{a}}, \mathrm{II}_{\mathrm{b}}\right)$ was obtained by placing 5-\% polyamide-NMP solution on a glass plate and by keeping the plate at $150^{\circ} \mathrm{C}$ for $0.5 \mathrm{hr}$. Polyamide film was heated further at $250^{\circ} \mathrm{C}$ for $30 \mathrm{~min}, 230-330^{\circ} \mathrm{C}(5 \mathrm{~mm})$ for $1 \mathrm{hr}$.

Thermal Cyclization of Polyamide $\left(I I_{a}, I I_{b}\right)$ in the Presence of Zinc Chloride. (a) In the case of $\mathrm{II}_{\mathrm{a}}$ : Polybenzoxazinone $\left(\mathrm{II}_{\mathrm{a}}\right)$. Polyamide $\left(\mathrm{II}_{\mathrm{a}}\right)$ film containing $10-w t \%$ zinc chloride to polymer was obtained by adding zinc chloride to the 5-wt $\%$ polyamide-NMP solution and holding for $1 \mathrm{hr}$ at $150^{\circ} \mathrm{C}$. This film was then heated at $230-330^{\circ} \mathrm{C}$ for $30 \mathrm{~min}$. (b) In the case of $\mathrm{II}_{\mathrm{b}}$ : Polyquinazolone $\left(\mathrm{III}_{\mathrm{b}}\right)$. The same amounts of catalyst were used. After cyclization at $250^{\circ} \mathrm{C}$ $(1 \mathrm{~mm})$ for $1.5 \mathrm{hr}$, followed by $300^{\circ} \mathrm{C}(1 \mathrm{~mm})$ for $2 \mathrm{hr}$, the zinc chloride was removed by treating the film in a 10-\% aqueous hydrogen chloride solution.

Thermal Cyclization of Polyamide $\left(I_{a}\right)$ in the Presence of Lithium Chloride to Polyquinazolone $\left(I I I_{a}\right)$. Ten-wt $\%$ of lithium chloride to polymer was added to the polyamide-NMP solution to make film. After heating the film at 300$330^{\circ} \mathrm{C}$ for $1 \mathrm{hr}$, the polymer film was dipped in water to remove lithium chloride.

\section{RESULTS AND DISCUSSION}

The Ring-Opening Reaction of Polybenzoxazinone with Organic Amine

In the polymer reaction of polybenzoxazinone 


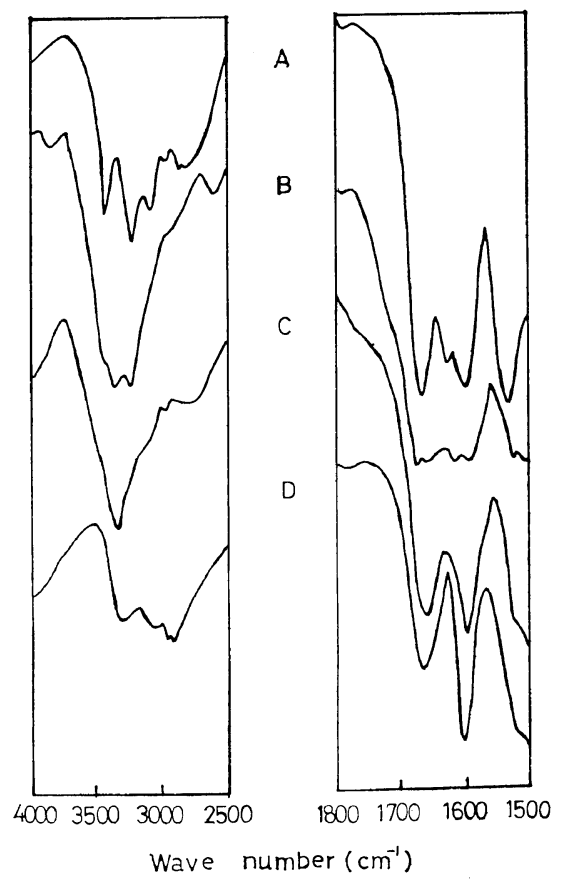

Figure 1. Infrared spectra of model compounds and polyamide having pendant amide groups: (A) $o$-(benzamide) benzamide $\left(\mathrm{II}_{\mathrm{a}}\right)$ (KBr disk), (B) polyamide prepared by the reaction of $4,4^{\prime}$-diamino-3,3'biphenyldicarboxylamide with 4,4'-oxydibenzoylchloride (film), (C) polyamide $\left(\mathrm{II}_{\mathrm{a}}\right)$ (film), (D) polyamide $\left(\mathbf{I I}_{\mathrm{b}}\right)$ (film). with an organic base such as liquid ammonia and aniline, it is presumed that the decrease in molecular weight of polymer occurs from the degradation of the polymer main chain by excess amine. Table I shows the result of the changes in molecular weight of the polymer from the reaction of polybenzoxazinone with amine.

In order to compare the molecular weight of polybenzoxazinone with that of polyamide, the inherent viscosity $\left(0.5-\% \mathrm{H}_{2} \mathrm{SO}_{4}, 25^{\circ} \mathrm{C}\right)$ of polyamide acid, precursor of polybenzoxazinone, was measured in $\mathrm{H}_{2} \mathrm{SO}_{4}$ and compared with that of polyamide. The decrease in molecular weight in liquid ammonia is moderated, whereas in aniline an appreciable decrease in molecular weight was observed. The structure of polyamide was confirmed by the infrared spectra and elemental analyses. The infrared absorption bands of the polyamide were compared with those of model compounds in the region of 2500-4000 $\mathrm{cm}^{-1}$ and $1500-1800 \mathrm{~cm}^{-1}$ as shown in Figure 1.

The carbonyl absorptions of polyamide $\left(\mathrm{II}_{\mathrm{a}}\right.$, $\mathrm{II}_{\mathrm{b}}$ ) appear at $1670 \mathrm{~cm}^{-1}$ and $1660 \mathrm{~cm}^{-1}$, which is closely related to the compound (IV) and the authentic sample of polyamide (II) prepared from 4,4'-diamino-3, 3'-biphenyldicarboxylamide and $4,4^{\prime}$-oxydibenzoyl chloride. The result of the elemental analyses are shown in Tables II and III.

Tabie I. The changes of molecular weight by the reaction of polybenzoxazinone with amine

\begin{tabular}{|c|c|c|c|c|c|c|c|}
\hline \multirow{2}{*}{$\begin{array}{l}\text { Expt } \\
\text { no. }\end{array}$} & \multirow{2}{*}{$\begin{array}{c}\text { Polyamide acid, } \\
\eta_{\text {inh }}\left(\mathrm{H}_{2} \mathrm{SO}_{4}, 0.5 \%, 25^{\circ} \mathrm{C}\right)\end{array}$} & \multirow{2}{*}{\multicolumn{2}{|c|}{$\begin{array}{l}\text { Polybenzoxazinone } \\
\text { cyclization condition, } \\
{ }^{\circ} \mathrm{C}(\mathrm{mmHg}): \mathrm{hr}\end{array}$}} & \multicolumn{3}{|c|}{ Ring opening reaction } & \multirow{2}{*}{$\begin{array}{l}\text { Polyamide having pend- } \\
\text { ant amide groups, } \\
\eta_{\text {inh }}\left(\mathrm{H}_{2} \mathrm{SO}_{4}, 0.5 \%, 25^{\circ} \mathrm{C}\right)\end{array}$} \\
\hline & & & & Amine & $\begin{array}{c}\text { Condition, } \\
{ }^{\circ} \mathrm{C} / \mathrm{hr}\end{array}$ & $\underset{\%}{\text { Yield, }}$ & \\
\hline 1 & 1.0 & $300 / 1$ & 1 & liq. $\mathrm{NH}_{3}$ & $-86 / 24$ & 98 & 0.73 \\
\hline 2 & 0.57 & $230 / 1$ & 1 & Aniline & $184-186 / 4$ & 96 & 0.24 \\
\hline
\end{tabular}

Table II. Elemental analyses of polymer $\left(\mathrm{NH}_{3}\right.$ series $)$

\begin{tabular}{|c|c|c|c|c|c|}
\hline No. & & Polymer & $\mathrm{C}, \%$ & $\mathbf{H}, \%$ & $\mathrm{~N}, \%$ \\
\hline 1 & \multirow{3}{*}{ Calcd } & Polybenzoxazinone & 73.36 & 3.08 & 6.11 \\
\hline 2 & & Polyamide $\left(\mathrm{II}_{\mathrm{a}}\right)$ & 68.28 & 4.09 & 11.38 \\
\hline 3 & & Polyquinazolone $\left(\mathrm{II}_{\mathrm{a}}\right) \quad\left(\mathrm{C}_{28} \mathrm{H}_{16} \mathrm{O}_{3} \mathrm{~N}_{4}\right)$ & 69.69 & 4.07 & 14.14 \\
\hline 4 & \multirow{4}{*}{ Found } & (Polyamide (authentic sample) & 68.01 & 4.38 & 11.06 \\
\hline 5 & & Polyamide $\left(\mathrm{II}_{\mathrm{a}}\right)$ & 68.11 & 4.45 & 11.05 \\
\hline 6 & & Polybenzoxazinone & 73.21 & 3.35 & 6.05 \\
\hline 7 & & Polyquinazolone $\left(\mathrm{III}_{\mathrm{a}}\right)$ & 69.98 & 3.78 & 13.86 \\
\hline
\end{tabular}


Cyclopolycondensation. XIII. Syntheses of Polyquinazolones

Table III. Elemental analyses of polymer (aniline series)

\begin{tabular}{rlllll}
\hline No. & \multicolumn{1}{c}{ Polymer } & $\mathrm{C}, \%$ & $\mathrm{H}, \%$ & $\mathrm{~N}, \%$ \\
\hline 1 & \multirow{2}{c}{ Calcd $\left\{\begin{array}{llll}\text { Polybenzoxazinone } \\
\text { Polyamide }\left(\mathrm{II}_{\mathrm{b}}\right)\end{array}\right.$} & $\left(\mathrm{C}_{28} \mathrm{H}_{14} \mathrm{O}_{5} \mathrm{~N}_{2}\right)$ & 73.36 & 3.08 & 6.11 \\
2 & $\left(\mathrm{C}_{40} \mathrm{H}_{28} \mathrm{O}_{5} \mathrm{~N}_{4}\right)$ & 74.52 & 4.72 & 8.69 \\
3 & Polyquinazolone $\left(\mathrm{III}_{\mathrm{b}}\right)$ & $\left(\mathrm{C}_{40} \mathrm{H}_{28} \mathrm{O}_{3} \mathrm{~N}_{4}\right)$ & 78.99 & 3.95 & 9.21 \\
4 & \multirow{2}{*}{ Found } & & 73.95 & 4.72 & 8.01 \\
6 & & 73.10 & 3.35 & 6.58 \\
Polyamide $\left(\mathrm{II}_{\mathrm{b}}\right)$ & & 78.32 & 4.01 & 8.90 \\
\hline
\end{tabular}

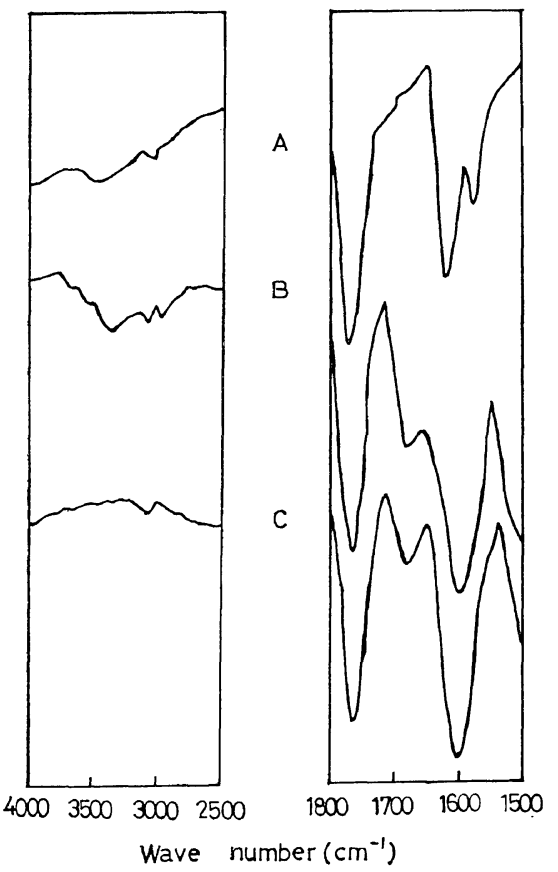

Figure 2. Infrared spectra of model compounds and polybenzoxazinones: (A) 2-phenyl-4H-3,1-benzoxazine-4-one(IV), (B) polybenzoxazinone prepared by the thermal cyclization of polyamide acid (film), (C) polybenzoxazinone prepared by the thermal cyclization of polyamides $\left(\mathbf{I I}_{a}, \mathbf{I I}_{b}\right)$ (film).

\section{The Thermal Cyclization of Polyamide}

Synthesis of model compounds and the model reaction described in the experimental sections, suggested that the cyclization of polyamide by thermal treatment involves two processes: (1) In the absence of a catalyst, thermal deamination occurs to yield the polybenzoxazinone; (2) In the presence of catalyst, the dehydration occurs to yield the polyquinazolone. The differences between the deamination and the dehydration

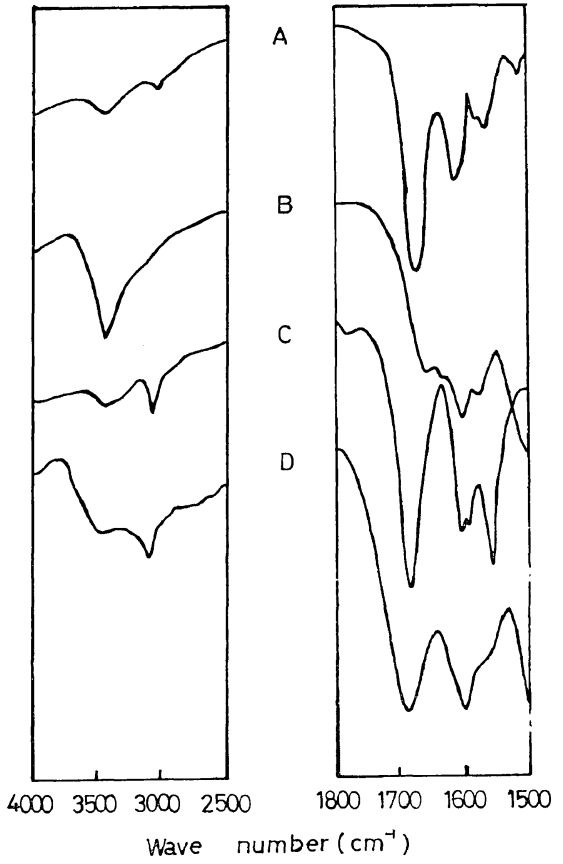

Figure 3. Infrared spectra of model compounds and polyquinazolone: (A) 2-phenyl-4(3H)-quinazolone (VI) ( $\mathrm{KBr}$ disk), (B) polyquinazolone $\left(\mathrm{III}_{\mathrm{a}}\right)$ (film), (C) 2,3-diphenyl-4(3H)-quinazolone (VII) $\left(\mathrm{KBr}\right.$ disk), (D) polyquinazolone $\left(\mathrm{III}_{\mathrm{b}}\right)($ film),

by the thermal treatment of the polyamide were confirmed by the following evidence: (1) The comparison of IR spectra of the polymer obtained with those of model compounds and the authentic sample; (2) the thermal gravimetric analyses, and (3) the elemental analyses.

Figure 2 shows the strong carbonyl absorption band of polybenzoxazinone (I) obtained from polyamides $\left(\Pi_{a}, \Pi_{b}\right)$ at $1760 \mathrm{~cm}^{-1}$, which is the characteristic absorption band of benzoxazinone. ${ }^{1-3}$ 


\section{Kurihara and Y. Hagiwara}

The carbonyl absorption band at $1680 \mathrm{~cm}^{-1}$ indicates that the polymer contains appreciable amounts of the uncyclized polyamide structure having pendant amide groups. From the data in the infrared spectra of the quinazolone system ${ }^{8}$ and Figure 3, the carbonyl absorption of $\mathrm{III}_{\mathrm{a}}$ appear at $1670 \mathrm{~cm}^{-1}$ and $1610 \mathrm{~cm}^{-1}$, which correspond to the carbonyl group and the $\mathrm{C}=\mathrm{N}$ group of 4-quinazolone, respectively. The carbonyl absorption band of III $_{\mathrm{b}}$ appears at $1670 \mathrm{~cm}^{-1}$, which is assigned to the carbonyl group of quinazolone.

In the polyamide $\left(\mathrm{II}_{\mathrm{a}}\right)$, the theoretical percentage of weight loss is $6.80 \%$ in the deamination, and $7.32 \%$ in the dehydration, respectively. In the polyamide $\left(\mathrm{II}_{\mathrm{b}}\right)$, the theoretical percentage of weight loss is $29.2 \%$ in the deamination, and $5.59 \%$ in the dehydration, respectively. The decrease of polyamide by thermal treatment in air closely agrees with that of the theoretical percentage of weight loss (Figure 4). The deamination and dehydration are also confirmed by data from elemental analyses as shown in Tables II and III. Recently, Sillion, et al. ${ }^{10,11}$ reported that in the thermal cyclization of the polyamide $\left(\mathrm{II}_{\mathrm{a}}\right)$, deamination and dehydration occur to yield a mixture of both polyquinazolone $\left(\mathrm{III}_{\mathrm{a}}\right)$ and diimide structure, in the absence of catalyst, by comparing IR spectra of the polymer with those of model compounds. The structure of the polymer is different in

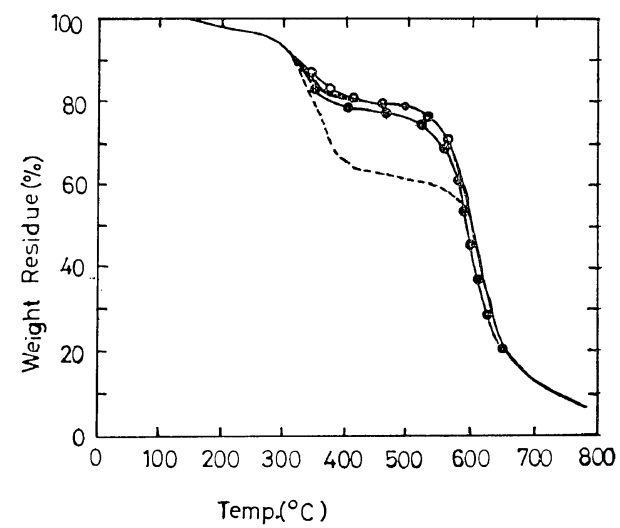

Figure 4. Thermal gravimetric analysis curves of polyamide having pendant amide groups in air: $-\mathrm{O}-\mathrm{O}-$, polyamide $\left(\mathrm{II}_{\mathrm{a}}\right) ;-\mathrm{-}-\mathrm{O}-$, polymide $\left(\mathrm{II}_{\mathrm{a}}\right)$ with $\mathrm{LiCl}$; - $\longrightarrow$, polyamide $\left(\mathrm{II}_{\mathrm{b}}\right)$ with $\mathrm{ZnCl}_{2}$; --- , polyamide $\left(\mathrm{II}_{\mathrm{b}}\right)$. part from the present experiment. They reported that the diimide structure has two carbonyl absorption bands at 1770 and $1740 \mathrm{~cm}^{-1}$ in the model compounds. In their IR spectra of the polymer, no two carbonyl absorption bands were observed at 1740 and $1720 \mathrm{~cm}^{-1}$, and the carbonyl absorption band appeared at $1750 \mathrm{~cm}^{-1}$, which is the characteristic absorption band of polybenzoxazinone. ${ }^{3}$

From the data discussed in this experiment, it is interesting to find that the reaction course of polyamides $\left(\mathrm{II}_{\mathrm{a}}, \mathrm{II}_{\mathrm{b}}\right)$ to follow dehydration or deamination reactions depends upon the use of an inorganic salt. It is presumed from the model reaction of IV with aniline in the presence of $\mathrm{ZnCl}_{2}$, and the polymer reaction of polybenzoxazinone with amine in the presence of inorganic salts, that the formation of a complex of ortho-substituted amide groups with inorganic salts is necessary to obtain the quinazolone ring.

The Properties of Polyamide and Polyquinazolone

The polyamides $\left(\mathbf{I}_{\mathrm{a}}, \mathrm{II}_{\mathrm{b}}\right)$ are soluble in $\mathrm{di}$ methylacetamide, N-methylpyrrolidone, dimethylformamide and dimethylsulfoxide. They are soluble in concentrated sulfuric acid. The polyquinazolone $\left(\mathrm{III}_{a}, \mathrm{III}_{\mathrm{b}}\right)$ is insoluble in most organic solvents: it is soluble in fuming nitric acid and concentrated sulfuric acid. The thermogravimetric analyses of the polyamides $\left(\mathrm{II}_{a}, \mathrm{II}_{\mathrm{b}}\right)$ (Figure 4) show that intramolecular deamination takes place at $270^{\circ} \mathrm{C}$ to form poly-

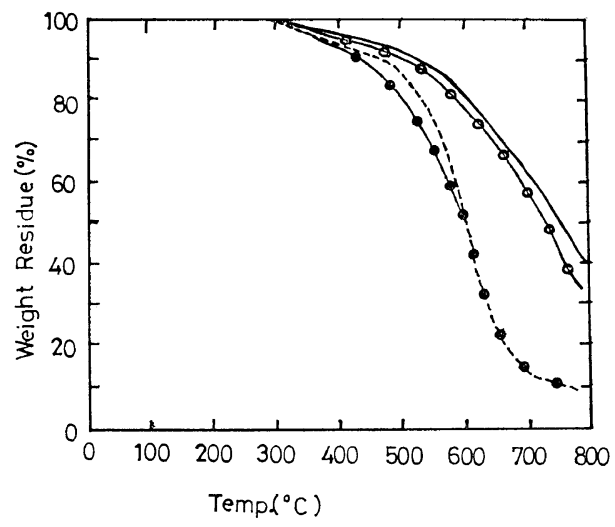

Figure 5. Thermal gravimetric analysis curves of polyquinazolone: $\longrightarrow$, polyquinazolone $\left(\mathrm{III}_{\mathrm{b}}\right)$ in nitrogen; - - - , polyquinazolone $\left(\mathrm{III}_{\mathrm{b}}\right)$ in air; $-\mathrm{O}-\mathrm{O}-$, polyquinazolone $\left(\mathrm{III}_{\mathrm{a}}\right)$ in nitrogen; -1-, polyquinazolone $\left(\mathrm{III}_{\mathrm{a}}\right)$ in air. 
Cyclopolycondensation. XIII. Syntheses of Polyquinazolones

benzoxazinone, and that intramolecular dehydration occurs at $280^{\circ} \mathrm{C}$ to form polyquinazolone $\left(\mathrm{III}_{\mathrm{a}}, \mathrm{III}_{\mathrm{b}}\right)$. The thermal stabilities of polyquinazolone $\left(\mathrm{III}_{\mathrm{a}}, \mathrm{III}_{\mathrm{b}}\right)$ were measured either in nitrogen or in air by the thermogravimetric method, as shown in Figure 5. These quinazolone polymers have excellent thermal stability and decomposition begins from about $380^{\circ} \mathrm{C}$ in nitrogen.

Acknowledgment. The authors gratefully acknowledge the interest and encouragement shown by Dr. N. Yoda of Pioneering Research and Development Laboratories, Toray Ind. Inc. The authors are indebted to Messrs. Y. Ebata and T. Mizushina for microanalyses and thermogravimetric analyses.

\section{REFERENCES}

1. M. Kurihara, H. Saito, K. Nukada, and N.
Yoda, J. Polym. Sci., Part A-1, 7, 2829 (1969).

2. N. Yoda, M. Kurihara, K. Ikeda, S. Tohyama, and R. Nakanishi, ibid., Part B, 4, 551 (1966).

3. M. Kurihara and N. Yoda, J. Macromol. Sci., A6, 1069 (1967).

4. N. Yoda, K. Ikeda, M. Kurihara, S. Tohyama, and R. Nakanishi, J. Polym. Sci., Part A-1, 5, 2359 (1967).

5. P. Friedländer and $\mathrm{S}$. Wleugel, Ber, 16, 2227 (1883).

6. D. T. Zentmyer and E. C. Wagner, J. Org. Chem., 14, 967 (1949).

7. M. T. Bogert, R. A. Gortner, and C. G. Amend, J. Amer. Chem. Soc., 33, 951 (1911).

8. Y. Hagiwara, M. Kurihara, and N. Yoda, Tetrahedron, 25, 783 (1968).

9. M. Kurihara and N. Yoda, J. Polym. Sci., Part B, 6, 875 (1968).

10. B. Sillion and G. de Gaudemaris, Entropie, $\mathbf{N}$ 21, 67 (1968).

11. P. G. Rabilloud, B. Sillion, and G. de Gaudemaris, Makromol. Chem., 125, 264 (1969). 